\title{
Variation in the Resistance of Japanese Soybean Cultivars to Phytophthora Root and Stem Rot during the Early Plant Growth Stages and the Effects of a Fungicide Seed Treatment
}

\author{
Hajime Akamatsu (iD) ${ }^{1 *}$, Masayasu Kato ${ }^{2}$, Sunao Ochi ${ }^{3,4}$, Genki Mimuro ${ }^{3,5}$, Jun-ichi Matsuoka ${ }^{1}$, and \\ Mami Takahashi ${ }^{1}$ \\ ${ }^{l}$ Division of Lowland Farming, Hokuriku Research Center, Central Region Agricultural Research Center, National Ag- \\ riculture and Food Research Organization, 1-2-1 Inada, Joetsu, Niigata 943-0193, Japan \\ ${ }^{2}$ Biological Resources and Post-harvest Division, Japan International Research Center for Agricultural Sciences, 1-1 \\ Ohwashi, Tsukuba, Ibaraki 305-8686, Japan \\ ${ }^{3}$ Division of Plant Disease Management, Central Region Agricultural Research Center, National Agriculture and Food \\ Research Organization, 2-1-18 Kannondai, Tsukuba, Ibaraki 305-8666, Japan \\ ${ }^{4}$ Research Center for Agricultural Information Technology, National Agriculture and Food Research Organization, 3-5- \\ 1 Kasumigaseki, Chiyoda-ku, Tokyo 100-0013, Japan \\ ${ }_{5}^{5}$ Agricultural Research Institute, Toyama Prefectural Agricultural, Forestry and Fisheries Research Center, Toyama, \\ Toyama 939-8153, Japan
}

(Received on November 10, 2018; Revised on March 28, 2019; Accepted on April 7, 2019)

Soybean cultivars susceptible to Phytophthora root and stem rot are vulnerable to seed rot and damping-off of seedlings and young plants following an infection by Phytophthora sojae. In this study, the disease responses of Japanese soybean cultivars including currently grown main cultivars during the early growth stages were investigated following infections by multiple $P$. sojae isolates from Japanese fields. The extent of the resistance to $17 P$. sojae isolates after inoculations at 14,21 , and 28 days after seeding varied significantly among 18 Japanese and two US soybean cultivars. Moreover, the disease responses of each cultivar differed significantly depending on the $P$. sojae isolate and the plant age at inoculation. Additionally, the treatment of 'Nattosyo-ryu' seeds with three fungicidal agrochemicals provided

\section{*Corresponding author.}

Phone) +81-25-526-3243, FAX) +81-25-524-8578

E-mail) akamatho@affrc.go.jp

ORCID

Hajime Akamatsu

https://orcid.org/0000-0003-4402-8366

(c) This is an Open Access article distributed under the terms of the Creative Commons Attribution Non-Commercial License (http:// creativecommons.org/licenses/by-nc/4.0) which permits unrestricted noncommercial use, distribution, and reproduction in any medium, provided the original work is properly cited.

Articles can be freely viewed online at www.ppjonline.org. significant protection from $P$. sojae when plants were inoculated at 14-28 days after seeding. These results indicate that none of the Japanese soybean cultivars are completely resistant to all tested $\boldsymbol{P}$. sojae isolates during the first month after sowing. However, the severity of the disease was limited when plants were inoculated during the later growth stages. Furthermore, the protective effects of the tested agrochemicals were maintained for at least 28 days after the seed treatment. Japanese soybean cultivars susceptible to Phytophthora root and stem rot that are grown under environmental conditions favorable for $\boldsymbol{P}$. sojae infections require the implementation of certain practices, such as seed treatments with appropriate agrochemicals, to ensure they are protected from $P$. sojae during the early part of the soybean growing season.

Keywords : chemical control, Glycine max, partial resistance, Rps gene, zoospore

Handling Editor : Jeon, Junhyun

Soybean [Glycine $\max$ (L.) Merrill], which is one of the most important crops worldwide, is an economically important legume used as a source of oil, feed, and protein (Hart- 
man et al., 2011). Soybean production in 2016 exceeded 330 million tons (FAOSTAT, 2016). In Asian countries, including Japan, soybean is an essential crop for traditional food products (Soyinfo Center: www.soyinfocenter.com). Between 2007 and 2016, Japan annually produced 199.9$261.7 \times 10^{3}$ tons, which placed the country 17 th- $23 \mathrm{rd}$ in the global ranking of soybean producers (FAOSTAT, 2016). However, this production level accounted for only $21-25 \%$ of the yield needed for the self-sufficient production of soybean as food. Therefore, the soybean industry in Japan is largely dependent on soybean imported from countries such as the US, Brazil, and Canada (FAOSTAT, 2016). Nonetheless, there has been a continuous demand for domestically grown conventional soybean, but soybean production has not increased in Japan for several decades. The temporal variation in average annual prefectural yields between 1958 and 2016 ranged from 0.94 to 1.66 tons per hectare, and annual yields have not increased in $89 \%$ of the analyzed prefectures (Chen, 2018). The obstacles that have prevented improvements in soybean production have included diverse abiotic and biotic factors such as extremes in nutrient availability, temperature, and moisture as well as diseases, pests, and weeds (Hartman et al., 2011).

One of the biotic constraints that can decrease soybean seed yield and/or quality is Phytophthora root and stem rot caused by Phytophthora sojae Kaufmann and Gerdemann [synonyms: Phytophthora megasperma var. sojae, $P$. megasperma f. sp. glycinea, and P. sojae f. sp. glycines], which has threatened soybean production worldwide (Grau et al., 2004; Hansen and Maxwell, 1991; Kaufmann and Gerdemann, 1958; Schmitthenner and Dorrance, 2015; Tyler, 2007; Wrather et al., 2001a). In 1998, the soybean yield in the top-10 soybean-producing countries decreased by an estimated 1,266 $\times 10^{3}$ tons because of Phytophthora root and stem rot (Wrather et al., 2001a). In the US, the second largest decrease in soybean yield (an estimated 3,709 $\times 10^{3}$ tons) occurred between 1996 and 1998, and was caused by Phytophthora root and stem rot (Wrather et al., 2001b). A survey conducted from 1996 to 2007 revealed that Phytophthora root and stem rot was the second and third worst diseases in terms of yield losses in 7 and 4 out of the 12 years, respectively (Wrather and Koenning, 2009). In Japan, this disease spread to several prefectures within 10 years of its first occurrence in 1977 (Sugimoto et al., 2006, 2012), and has since become a nationwide concern among soybean producers. Significant yield losses attributed to the disease have been reported in the top-10 soybean-producing countries as well as in Australia and Japan (Schmitthenner and Dorrance, 2015).

Phytophthora sojae, which is a homothallic oomycete classified in the kingdom Stramenopiles (Dorrance, 2018; Förster et al., 1990; Harper et al., 2005; Tyler, 2007), grows saprophytically and readily produces sexual oospores in soil and infected plant tissue. The oospores can survive in soil and diseased plant debris for extended periods (Dorrance et al., 2007; Tyler, 2007), suggesting that soybean plants grown in fields previously infected with Phytophthora root and stem rot are continuously at risk of developing the disease. The mycelia grown in soil and infected plant tissue produce asexual spores called sporangia, in which motile zoospores are generated. The zoospores are released from the sporangia under waterlogged conditions, after which they differentiate to form adhesive cysts that can infect soybean plants. The pathogen repeats its life cycle via a secondary infection during a soybean growing season under favorable environmental conditions. Because the infection by zoospores is essential to initiate the parasitic phase of the $P$. sojae life cycle, fields saturated for a long time provide one of the most ideal conditions for inducing Phytophthora root and stem rot. In Japan, most soybean plants are cultivated in fields converted from rice paddies (Kato et al., 2013; Sugimoto et al., 2012). Such soybean fields usually contain poorly drained soil with a high moisture level, which is ideal for a $P$. sojae infection and subsequent multiplication. Kato et al. (2013) reported that $P$. sojae is involved in pre-emergence soybean seedling damping-off in fields converted from rice paddies. Thus, soybean cultivars that are susceptible to the disease require the application of cultural and/or chemical practices to control P. sojae.

Host resistance to $P$. sojae, which is one of the most economical and environmentally friendly disease control measures, has been well-studied, especially for major resistance (R) gene-mediated resistance involving the race-specific interactions between soybean and P. sojae (Dorrance, 2018; Dorrance et al., 2007; Grau et al., 2004; Sugimoto et al., 2012). Previous studies identified 20 or more $\mathrm{R}$ genes or alleles (Rps: resistance to $\underline{P}$. sojae), some of which have been commercially deployed to manage the disease in soybean fields (Dorrance, 2018; Jiang et al., 2017). In addition to the Rps-mediated resistance, soybean plants express partial resistance (i.e., quantitative resistance, field resistance, ratereducing resistance, or tolerance) in a race-non-specific manner that is effective against all $P$. sojae races (Anderson and Buzzell, 1982; Dorrance, 2018; Schmitthenner, 1985; Sugimoto et al., 2012; Tooley and Grau, 1982, 1984). Unlike Rps-mediated resistance, this incomplete resistance leads to different levels of susceptibility/resistance among cultivars and can be evaluated based on decreased infection or colonization efficiency, the development of smaller lesions, and the production of fewer oospores in infected 
plant tissue (Dorrance, 2018; Mideros et al., 2007). In the US, soybean germplasm exhibiting various levels of partial resistance has been identified by screening the plant introduction series of the soybean germplasm collection belonging to the US Department of Agriculture (Dorrance and Schmitthenner, 2000; Jia and Kurle, 2008; Schneider et al., 2016). Several quantitative trait loci have been detected (Abeysekara et al., 2016; Burnham et al., 2003; Lee et al., 2013a, 2013b; Schneider et al., 2016; Tucker et al., 2010; Wu et al., 2011). Meanwhile, partial resistance among Japanese soybean cultivars has been studied mainly in Hokkaido and Hyogo prefectures, and six cultivars and one cultivar, respectively, were selected as candidates exhibiting a high level of partial resistance (Sugimoto et al., 2012; Yamashita et al., 2012). However, the tested cultivars or lines were limited to those grown locally.

Partial resistance against Phytophthora root and stem rot is not expressed in the soybean seed, but is effective during the growth stage in which the first trifoliate leaf is formed as well as in the subsequent stages (Schmitthenner and Dorrance, 2015). The resulting primary symptom is decreased root colonization (Dorrance et al., 2007). Additionally, 'Hark' plants (i.e., susceptible cultivar) inoculated at 16 days after seeding are more resistant to Phytophthora root and stem rot than younger plants (Jimenez and Lockwood, 1980). Meanwhile, one of the best-studied cultivars regarding this type of resistance, 'Conrad', which lacks Rps genes, is initially susceptible, but then becomes highly tol- erant to $P$. sojae (Fehr et al., 1989), with significantly less seedling emergence when plants are inoculated up to 5 days after seeding compared with inoculations at 7, 10, and 14 days (Dorrance and McClure, 2001). Thus, soybean plants without effective Rps genes are susceptible to $P$. sojae during the early vegetative growth phase when the characteristic disease symptoms, including seed rot and pre- and postemergence damping-off of seedlings and young soybean plants, are induced by the pathogen. Accordingly, characterizing the interactions between soybean cultivars and $P$. sojae in the seedling and early growth stages is important for developing effective disease management strategies because the onset of disease in the early part of the soybean growing season leads to direct plant losses and the need for costly replanting to replace soybean stands.

In this study, we analyzed the disease responses of soybean cultivars currently grown in Japan, including the major cultivars in terms of planted area, during the early growth stages. Our investigation involved multiple $P$. sojae isolates from Japanese soybean fields. We also examined the efficacy of commercially available pesticides applied to seeds to provide protection against Phytophthora root and stem rot. The objectives of this study were to (i) reveal the differences in the resistance to Phytophthora root and stem rot among Japanese soybean cultivars during the early growth stages, and (ii) determine the effective period for seed treatments with pesticides. The data presented herein demonstrate that seed treatments involving effective pesti-

Table 1. Phytophthora sojae isolates used in this study

\begin{tabular}{|c|c|c|c|}
\hline Code & Location & Isolation date & Isolation origin \\
\hline Ps060626-4-1 & Furukawa, Osaki, Miyagi & June 26, 2006 & Tanrei \\
\hline Ps060629-5-1 & Ogou, Imizu, Toyama & June 29, 2006 & Enrei \\
\hline Ps060726-2-1 & Higashiyonou, Chikusei, Ibaraki & July 26, 2006 & Nattosyoryu \\
\hline Ps080806-3-5 & Minatomachi-Shizukata, Aizu-Wakamatsu, Fukushima & August 6, 2008 & - \\
\hline 13-B-RO-1 & Kannondai, Tsukuba, Ibaraki & September 20, 2013 & Himeshirazu \\
\hline 13-B-RO-2 & Kannondai, Tsukuba, Ibaraki & September 20, 2013 & Tanbakuro \\
\hline 13-7-B1-1 & Hikawa, Tsukuba-Mirai, Ibaraki & 2013 & Nattosyoryu \\
\hline $13-8-11-2$ & Tamura, Tsukuba-Mirai, Ibaraki & 2013 & Tachinagaha \\
\hline Ps1001 & Kihara, Miura, Inashiki, Ibaraki & August 23, 2010 & Tachinagaha \\
\hline $59-3-2$ & Iitagawa-Iizuka, Katagami, Akita & February 6, 2014 & Ryuhou $^{\mathrm{a}}$ \\
\hline $66-1$ & Kanbayashi, Matsumoto, Nagano & February 21, 2014 & Nakasennari $^{\mathrm{a}}$ \\
\hline $69-2$ & Kanbayashi, Matsumoto, Nagano & February 21, 2014 & Nakasennari $^{\mathrm{a}}$ \\
\hline $90-1-3$ & Nijomasue, Itoshima, Fukuoka & March 7, 2014 & Fukuyutaka $^{\mathrm{a}}$ \\
\hline $97-1-2$ & Nakasokoino, Nakama, Fukuoka & March 7, 2014 & Fukuyutaka $^{\mathrm{a}}$ \\
\hline $103-3$ & Nanatsue, Yanagawa, Fukuoka & March 10, 2014 & Fukuyutaka $^{\mathrm{a}}$ \\
\hline $117-3-2$ & Kawasoe, Saga, Saga & March 21, 2014 & Fukuyutaka $^{\mathrm{a}}$ \\
\hline $129-2-3$ & Shiota, Ureshino, Saga & March 27, 2014 & Fukuyutaka $^{\mathrm{a}}$ \\
\hline
\end{tabular}

a Soybean cultivars grown in the fields from which the soil samples for isolation of Phytophthora sojae were collected. 
cides are important for protecting soybean plants from a $P$. sojae infection during the seedling and early growth stages.

\section{Materials and Methods}

Phytophthora sojae cultures. The following five $P$. sojae isolates were obtained from symptomatic soybean plants collected in Ibaraki prefecture, Japan in 2006-2014: 13B-RO-1, 13-B-RO-2, 13-7-B1-1, 13-8-11-2, and Ps1001 (Table 1). We isolated $P$. sojae as previously described by Sugimoto et al. (2006), but with some modifications to the contents of the V8 juice agar medium. Diseased soybean stems were washed with tap water or sterile distilled water, after which stem sections containing the edge of lesions and the adjacent healthy part were excised. The stem sections were immersed in 70\% ethanol for $10-20 \mathrm{~s}$ and $0.5 \%$ sodium hypochlorite for 1-2 min and then rinsed twice with sterile distilled water. After air-drying on sterile filter paper, the stem sections were placed on BNPRA-V8 juice agar medium (200 ml V8 juice, $3 \mathrm{~g} \mathrm{CaCO}_{3}, 1.5 \%$ agar, $10 \mathrm{mg} /$
1 benomyl, $10 \mathrm{mg} / 1$ nystatin, $7.5 \mathrm{mg} / 1$ pentachloronitrobenzene, $5 \mathrm{mg} / \mathrm{l}$ rifampicin, and $500 \mathrm{mg} / \mathrm{l}$ ampicillin) supplemented with $50 \mathrm{mg} / 1$ 3-hydroxy-5-isoxazole. Samples were then maintained at $25^{\circ} \mathrm{C}$ in a Cool Incubator (Mitsubishi Electric Engineering Co., Ltd., Tokyo, Japan). Mycelial tips derived from the stem pieces were transferred to Petri plates containing fresh BNPRA-V8 juice agar medium supplemented with $50 \mathrm{mg} / 1$ 3-hydroxy-5-isoxazole. For each isolate, the elongating hyphal tips were transferred to fresh V8 juice agar medium and grown at $25^{\circ} \mathrm{C}$ in a Cool Incubator.

Four of the 17 isolates, Ps060726-2-1, Ps080806-3-5, Ps060626-4-1, and Ps060629-5-1, were collected from Ibaraki, Fukushima, Miyagi, and Toyama prefectures, respectively (Table 1), and were provided by the Hokuriku Research Center, Central Region Agricultural Research Center of the National Agriculture and Food Research Organization (CARC/NARO).

Eight $P$. sojae isolates were obtained from the soil collected from soybean fields in Akita, Nagano, Fukuoka,

Table 2. Soybean cultivars used in this study and their planted area in Japan in 2012-2015

\begin{tabular}{|c|c|c|c|c|c|c|c|c|c|c|c|c|}
\hline \multirow{3}{*}{$\begin{array}{l}\text { Ranking } \\
\text { for } \\
\begin{array}{l}\text { planted } \\
\text { ares }\end{array}\end{array}$} & \multicolumn{3}{|c|}{2012} & \multicolumn{3}{|c|}{2013} & \multicolumn{3}{|c|}{2014} & \multicolumn{3}{|c|}{2015} \\
\hline & \multirow[t]{2}{*}{ Cultivar } & \multicolumn{2}{|c|}{$\begin{array}{c}\text { Cultivation } \\
\text { area }\end{array}$} & \multirow[t]{2}{*}{ Cultivar } & \multicolumn{2}{|c|}{$\begin{array}{c}\text { Cultivation } \\
\text { area }\end{array}$} & \multirow[t]{2}{*}{ Cultivar } & \multicolumn{2}{|c|}{$\begin{array}{c}\text { Cultivation } \\
\text { area }\end{array}$} & \multirow[t]{2}{*}{ Cultivar } & \multicolumn{2}{|c|}{$\begin{array}{c}\text { Cultivation } \\
\text { area }\end{array}$} \\
\hline & & ha & $\%$ & & ha & $\%$ & & ha & $\%$ & & ha & $\%$ \\
\hline 1 & Fukuyutaka & 33,488 & 24.50 & Fukuyutaka & 33,467 & 25.98 & Fukuyutaka & 34,507 & 26.22 & Fukuyutaka & 35,571 & 25.05 \\
\hline 2 & Enrei & 14,756 & 10.80 & Enrei & 13,143 & 10.20 & Yukihomare & 12,118 & 9.21 & Yukihomare & 14,069 & 9.91 \\
\hline 3 & Yukihomare & 10,764 & 7.87 & Yukihomare & 11,745 & 9.12 & Enrei & 11,831 & 8.99 & Enrei & 11,595 & 8.17 \\
\hline 4 & Ryuhou & 10,135 & 7.41 & Ryuhou & 10,013 & 7.77 & Ryuhou & 9,600 & 7.29 & Ryuhou & 10,295 & 7.25 \\
\hline 5 & Tachinagaha & 8,724 & 6.38 & Tachinagaha & 8,039 & 6.24 & Tachinagaha & 7,485 & 5.69 & Tachinagaha & 7,065 & 4.98 \\
\hline 6 & Osuzu & 4,160 & 3.04 & Miyagishirome & 4,760 & 3.70 & Miyagishirome & 4,439 & 3.37 & Satonohohoemi & 6,635 & 4.67 \\
\hline 7 & Miyagishirome & 4,137 & 3.03 & Osuzu & 4,147 & 3.22 & Satonohohoemi & 4,176 & 3.17 & Yukishizuka & 5,202 & 3.66 \\
\hline 8 & Sachiyutaka & 3,335 & 2.44 & Sachiyutaka & 3,462 & 2.69 & Osuzu & 4,064 & 3.09 & Miyagishirome & 4,701 & 3.31 \\
\hline 9 & Iwaikuro & 3,182 & 2.33 & Toyomusume & 3,034 & 2.36 & Yukishizuka & 3,791 & 2.88 & Osuzu & 4,578 & 3.22 \\
\hline 10 & Suzumaru & 3,008 & 2.20 & Iwaikuro & 3,006 & 2.33 & Sachiyutaka & 3,334 & 2.53 & Toyomusume & 4,066 & 2.86 \\
\hline- & Toyomusume & 2,817 & 2.06 & Suzumaru & 2,048 & 1.59 & Suzumaru & 1,940 & 1.47 & Sachiyutaka & 3,374 & 2.38 \\
\hline- & Tanbakuro & 2,781 & 2.03 & Tanbakuro & 2,861 & 2.22 & Toyomusume & 3,325 & 2.53 & Suzumaru & 1,906 & 1.34 \\
\hline- & Nattosyoryu & 1,741 & 1.27 & Nattosyoryu & 1,643 & 1.28 & Tanbakuro & 2,837 & 2.16 & Tanbakuro & 2,986 & 2.10 \\
\hline- & Tamahomare & 1,153 & 0.84 & Tamahomare & 1,099 & 0.85 & Nattosyoryu & 1,410 & 1.07 & Nattosyoryu & 1,183 & 0.83 \\
\hline- & Satonohohoemi & 1,102 & 0.81 & Satonohohoemi & 2,224 & 1.73 & Tamahomare & 1,033 & 0.78 & Tamahomare & 951 & 0.67 \\
\hline- & Suzuyutaka & 268 & 0.20 & Hatayutaka & 236 & 0.18 & Hatayutaka & 274 & 0.21 & Hatayutaka & 244 & 0.17 \\
\hline- & Hatayutaka & 238 & 0.17 & Suzuyutaka & 207 & 0.16 & Suzuyutaka & 120 & 0.09 & Suzuyutaka & & 0.01 \\
\hline- & Others & 31,417 & 22.98 & Others & 24,109 & 18.72 & Others & 25,710 & 19.54 & Others & 27,823 & 19.59 \\
\hline- & Total & 136,700 & 100 & Total & 128,800 & 100 & Total & 131,600 & 100 & Total & 142,000 & 100 \\
\hline
\end{tabular}

${ }^{a}$ Cultivars highlighted in dark and light grey were used in this study. The dark grey-highlighting cultivars were those ranked in top 10 of planted area in Japan. The statistical data was obtained from the governmental official website for Ministry of Agriculture, Forestry and Fisheries of Japan. The cultivation area (ha) represents the sum of the statistics for each cultivar in the data, whereas those for two cultivars: Himeshirazu and Toyokomachi were not determined due to no data available at the website. 
and Saga prefectures, Japan in 2014 (Table 1). The soil samples were maintained at room temperature in a plastic bag until used. 'Nattosyoryu' seeds were sown in plastic pots (1/10,000 a) filled with field soil. After 3-4 days under glasshouse conditions, the potted plants were flooded for $22 \mathrm{~h}$. Two days later, plants with Phytophthora root and stem rot lesions were collected for a subsequent isolation of $P$. sojae according to the above-mentioned procedure.

A PCR analysis using a species-specific primer pair (PSOJF1 and PSOJR1) (Bienapfl et al., 2011) confirmed that the expected amplicon was produced for all isolates except for four isolates provided by the Hokuriku Research Center, CARC/NARO. The four isolates from the Hokuriku Research Center have been already identified as $P$. sojae by means of morphological observation, PCR-based molecular characterization, and inoculation of soybean seedlings (Moriwaki, 2010).

Plant materials and seed treatment with pesticides. Eighteen Japanese soybean cultivars were used in this study (Table 2). Nine of the 18 cultivars ('Tachinagaha', 'Enrei', 'Fukuyutaka', 'Toyomusume', 'Ryuhou', 'Miyagishirome', 'Yukihomare', 'Satonohohoemi', and 'Osuzu') were among the 10 most planted soybean cultivars in Japan in 2015 (i.e., in terms of cultivated area). The nine other cultivars were as follows: 'Himeshirazu', 'Nattosyoryu', 'Suzumaru', 'Suzuyutaka', 'Tamahomare', 'Sachiyutaka', 'Toyokomachi', 'Tanbakuro', and 'Hatayutaka'. 'Suzumaru' and 'Sachiyutaka' were among the 10 most planted soybean cultivars in 2012 and 2012-2014, respectively. The statistical data was obtained from the governmental official website for Ministry of Agriculture, Forestry and Fisheries of Japan. The Rps genes have not been detected in these 18 Japanese cultivars, although some of the cultivars are reportedly resistant to certain $P$. sojae races (Jiang et al., 2017; Yamashita et al., 2012). Two US cultivars, 'Williams' and 'Harosoy', which lacks Rps genes (rps) and expresses low levels of partial resistance and possesses Rps7 (An- derson and Buzzell, 1992; Burnham et al., 2003; Wu et al., 2011), respectively, were also inoculated with Japanese $P$. sojae isolates.

Soybean seeds (approximately 25 seeds per cultivar) were sown in plastic pots $(1 / 10,000 \mathrm{a})$ containing $700 \mathrm{ml}$ vermiculite (Burnpiece, S size; Hakugen Earth, Tokyo, Japan), and covered with $200 \mathrm{ml}$ vermiculite. The vermiculite in pots was completely moistened with water, after which the pots were placed on a plastic tray (Sanko vat No. 1, 7 cm deep; Sanko Co., Ltd., Gifu, Japan). Water was then supplied to the plants through a hole at the bottom of the pots starting from 2-3 days after seeding. The pots were incubated in a glasshouse at CARC/NARO as described by Kato et al. (2013) to prepare the soybean plants for the inoculation test. To investigate the effects of pesticides on $P$. sojae, 'Nattosyoryu' seeds were treated with three commercially available pesticides (Table 3 ) at the recommended rates. The plants resulting from the pesticide-treated seeds were prepared for the inoculation test according to the above-mentioned procedure.

Inoculation and evaluation. Soybean plants were inoculated with $P$. sojae cultured on V8 juice agar medium as described by Mukobata and Sekihara (2006), with some modifications (i.e., $P$. sojae $-\mathrm{V} 8$ culture flooding method). Specifically, seven small pieces (approximately $5 \times 5 \mathrm{~mm}$ ) of a $P$. sojae culture grown on $\mathrm{V} 8$ juice agar medium were used to inoculate fresh V8 juice agar medium in $9 \mathrm{~cm}$ plastic Petri plates (Ina-Optika Co., Ltd., Osaka, Japan). The plates were incubated for 14 days at $25^{\circ} \mathrm{C}$ in an incubator. The $P$. sojae-V8 culture was roughly cut into small pieces (approximately $2 \times 2 \mathrm{~cm}$ ) using a spatula and then added to the vermiculite in each pot. The pots were flooded to approximately $2 \mathrm{~cm}$ above the vermiculite surface and then incubated for 5 days in the glasshouse. The inoculated plants were grown for an additional 5 days, during which plants were watered through a hole at the bottom of the pots. The inoculated soybean plants were evaluated

Table 3. Pesticides used in this study

\begin{tabular}{|c|c|c|c|c|}
\hline \multirow{2}{*}{ Pesticide $^{a}$} & \multirow{2}{*}{$\begin{array}{l}\text { Active ingredient } \\
\text { (a.i.) }\end{array}$} & \multicolumn{2}{|l|}{ Mode of action ${ }^{b}$} & \multirow{2}{*}{$\begin{array}{l}\text { Application } \\
\text { volume }\end{array}$} \\
\hline & & Target site (Code) & FRAC code & \\
\hline Vortex FS & Amisulbrom (50\%) & Complex III: cytochrome bc1 at Qi site (C4) & 21 & $8 \mathrm{ml} / \mathrm{kg}$ seed \\
\hline Cruiser MAXX ${ }^{\mathrm{d}}$ & Metalaxyl-M (1.7\%) & RNA polymerase I (A1) & 4 & $8 \mathrm{ml} / \mathrm{kg}$ seed \\
\hline Ranman flowable & Cyazofamid (10\%) & Complex III: cytochrome bc1 at Qi site (C4) & 21 & $20 \mathrm{ml} / \mathrm{kg}$ seed \\
\hline
\end{tabular}

${ }^{a}$ The three pesticides are manufactured by Nissan Chemical Industries, Ltd., Syngenta Japan K.K., and Ishihara Sangyo Kaisya, Ltd, respectively.

${ }^{\mathrm{b}}$ Mode of action of the pesticides is based on Fungicide Resistance Action Committee (2018).

${ }^{\mathrm{c}}$ The manufacturing of the product has been discontinued, and it has been excluded from agricultural chemical registration in 2016.

${ }^{\mathrm{d}}$ The product contains two additional ingredients: $1.1 \%$ fludioxonil and $22.6 \%$ thiamethoxam against fungal and insect pest, respectively. 


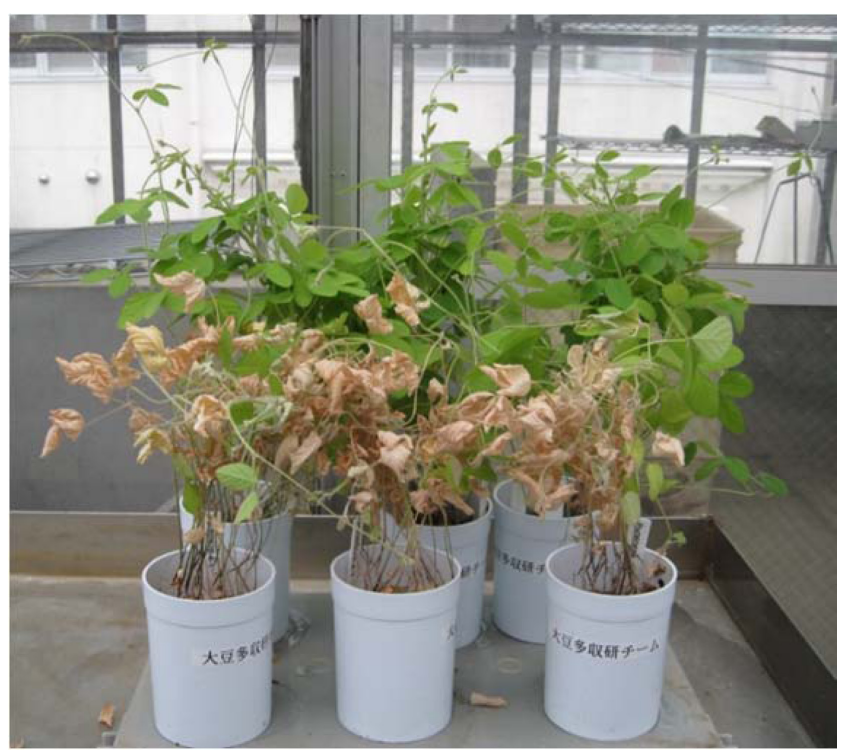

Fig. 1. Soybean plants inoculated with Phytophthora sojae cultured on V8 juice agar medium ( $P$. sojae-V8 culture flooding method). The photo shows 'Nattosyoryu' plants inoculated with Ps060626-4-1 isolate (the three pots in the front row) and treated with V8 agar as a control (the three pots in the back row). in terms of the number of dead plants per emerged plants. Example of the disease symptoms caused by the $P$. sojae inoculation is shown in Fig. 1. None of 'Nattosyoryu' plants treated with only V8 juice agar pieces died, while all 'Nattosyoryu' plants were killed by inoculation with the Ps060626-4-1-cultured V8 juice agar pieces (Fig. 1). The extent of the disease resistance among inoculation tests was compared based on the proportion of dead plants.

Data analysis. Data were analyzed using R software (version 3.4.4) (R Core Team, 2018). In the time course experiment, the rates of dead plants due to the $P$. sojae infection underwent an analysis of variance (ANOVA) for each soybean cultivar grown for a different number of days before being inoculated. To determine significant differences among the mean rates of dead plants, Tukey's honestly significant difference (HSD) test was completed by inputting the ANOVA results into the glht function of an R package, multcomp. The rates of dead plants due to the $P$. sojae infection were also compared among the 20 soybean cultivars using the above-mentioned method. In the time course evaluation of the efficacy of pesticide treatments of 'Nat-

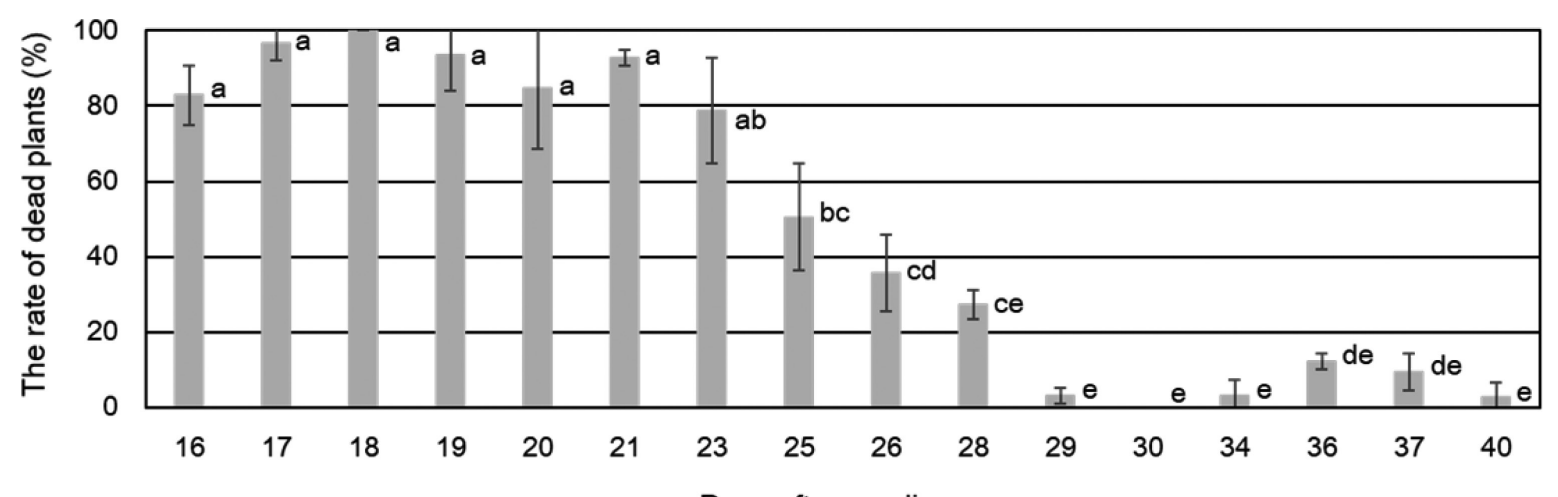

Days after seeding

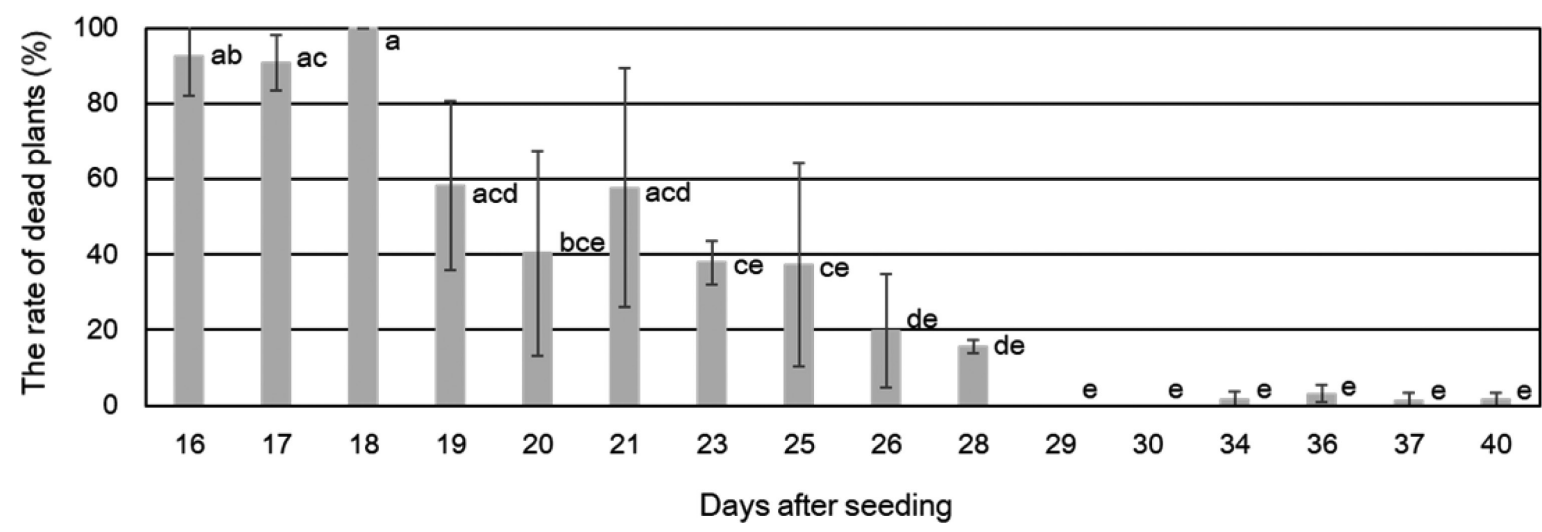

Fig. 2. Temporal changes in the rates of dead soybean plants (\%) following Phytophthora sojae inoculations of plants at different ages. Plants were inoculated with $P$. sojae isolate 13-B-RO-1 at 16-40 days after seeding. Mean values \pm standard errors for three inoculated pots are plotted in two graphs (top: 'Himeshirazu'; bottom: 'Nattosyoryu'). Mean values with the same letters in each graph are not significantly different according to Tukey’s honestly significant difference test $(p<0.05)$. 
tosyoryu' seeds, the rates of dead plants due to the $P$. sojae infection underwent an ANOVA for the non-treated control plants and the plants derived from seeds treated with one of three pesticides. Significant differences between the mean rates of dead plants for pesticide-treated and non-treated plants were determined by analyzing the ANOVA results with the glht function of multcomp according to Dunnett's multiple comparison test.

\section{Results}

In a preliminary inoculation test involving 20 soybean cultivars, 'Himeshirazu' and 'Nattosyoryu' appeared to be susceptible to $P$. sojae isolate 13-B-RO-1. The average rates of dead plants for 'Himeshirazu' and 'Nattosyoryu' were greater than $90 \%$ when these cultivars were inocu- lated at 14 days after seeding or earlier. None of the control soybean plants treated with only V8 juice agar or water developed disease symptoms (Fig. 1). To investigate the temporal changes in the disease resistance levels of the two cultivars, plants grown for 16-40 days after sowing were inoculated with $P$. sojae isolate 13-B-RO-1 (Fig. 2). On average, more than $75 \%$ of 'Himeshirazu' and 'Nattosyoryu' plants died following the inoculations at 16-23 days and 16-18 days after sowing, respectively. Compared with the data for the plants inoculated at highly susceptible ages, the rates of dead plants for 'Himeshirazu' and 'Nattosyoryu' significantly decreased when plants were inoculated at 2540 days and 26-40 days after sowing, respectively (Tukey's HSD test, $p<0.05$ ). The average rates of dead plants were less than $16 \%$ in 'Himeshirazu' plants grown for 29-40 days, and less than $5 \%$ in 'Nattosyoryu' plants grown for

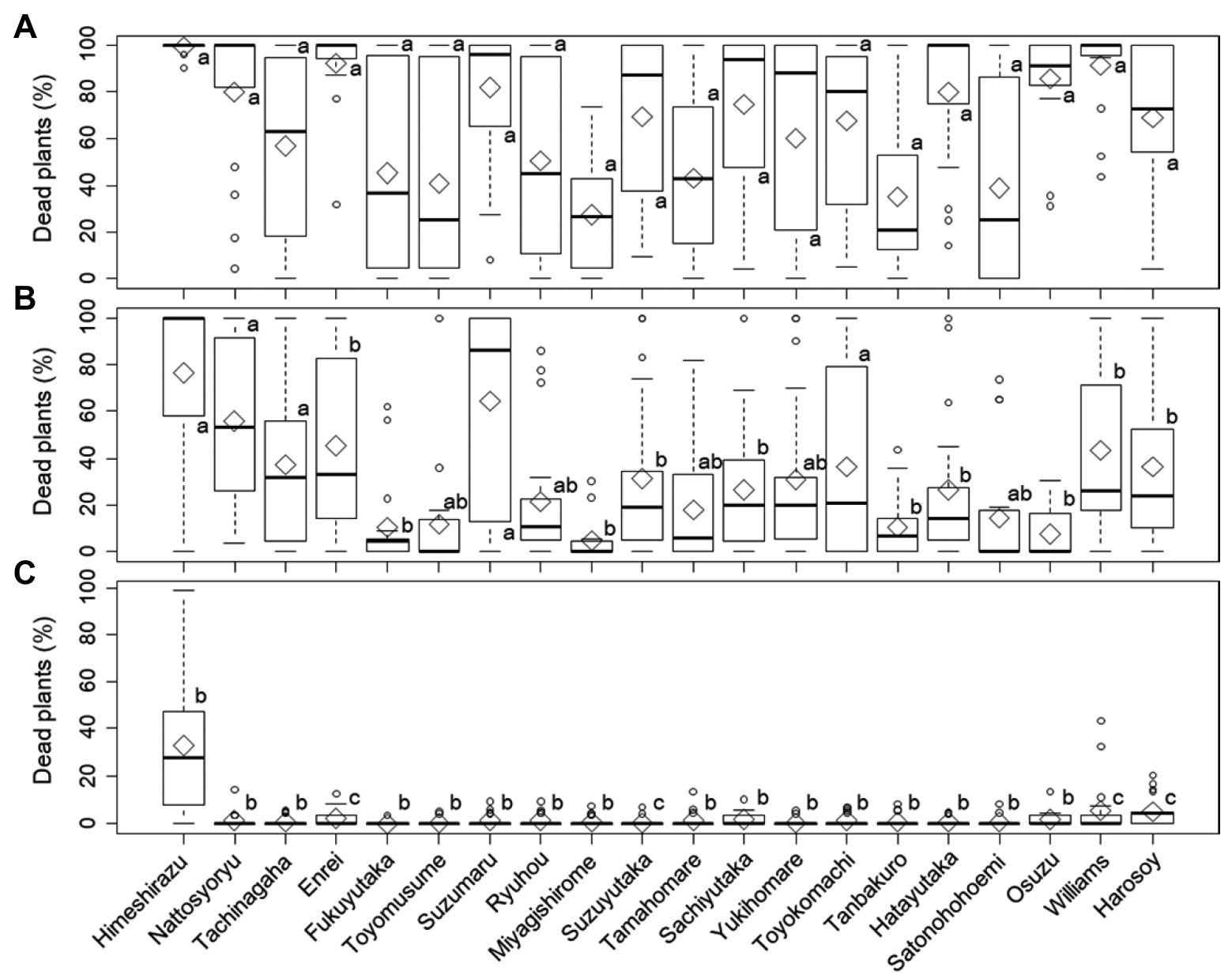

Fig. 3. Comparison of the resistance to Phytophthora root and stem rot among 20 soybean cultivars at different plant ages. Soybean plants were grown for 14, 21, or 28 days and then inoculated with one of 17 Phytophthora sojae isolates. The boxplots were drawn based on the rates of dead plants (\%) for the inoculation of plants grown for 14 days (A), 21 days (B), or 28 days (C). The open diamond in the plots indicates the average rate of dead plants for each cultivar. The mean values for each growth period were analyzed with Tukey's honestly significant difference test. The same letters in boxplots indicate the mean values are not significantly different among the three growth periods $(p<0.01)$. 


\section{9-40 days.}

To investigate whether the rates of dead plants decreased in other Japanese cultivars, the following 18 cultivars were challenged with $17 P$. sojae isolates from Japanese soybean fields (Table 1) at 14, 21, and 28 days after seeding (Fig. 3): 'Himeshirazu', 'Nattosyoryu', 'Tachinagaha', 'Enrei', 'Fukuyutaka', 'Toyomusume', 'Suzumaru', 'Ryuhou', 'Miyagishirome', 'Suzuyutaka', 'Tamahomare', 'Sachiyutaka', 'Yukihomare', 'Toyokomachi', 'Tanbakuro', 'Hatayutaka', 'Satonohohoemi', and 'Osuzu' (Table 2). Two US cultivars, 'Williams' and 'Harosoy', were also inoculated with the same isolates to investigate their responses to Japanese $P$. sojae isolates (Fig. 3). Inoculations at 14 days after seeding resulted in an average rate of dead plants that exceeded $75 \%$ for the following six Japanese cultivars: 'Himeshirazu', 'Nattosyoryu', 'Enrei', 'Suzumaru', 'Hatayutaka', and 'Osuzu'. The average rate of dead plants ranged from $27.7 \%$ to $74.8 \%$ for the 12 other Japanese cultivars. The extent of the resistance to the $17 P$. sojae isolates varied significantly among the 20 cultivars (ANOVA, $p<0.001$ ).

The average rate of dead plants decreased as the age of the plants when inoculated increased to 21 and 28 days after seeding. Moreover, there were significant differences in the extent of the resistance among cultivars for each age selected for inoculations (ANOVA, $p<0.001$ ). During the inoculation of plants at 21 days after seeding, 'Himeshirazu' was the only cultivar with an average rate of dead plants that was greater than $75 \%$. In contrast, 'Nattosyoryu', 'Enrei', and 'Suzumaru', which were also highly susceptible to disease when plants were inoculated at 14 days after seeding, had average rates of dead plants between $45.6 \%$ and $64.5 \%$. 'Hatayutaka' and 'Osuzu' had even lower average rates of dead plants, at $26.4 \%$ and $7.8 \%$, respectively. Of the plants inoculated at 14 days after seeding, only 'Miyagishirome' had an average rate of dead plants less than $30 \%$. Meanwhile, during the inoculations at 21 days after seeding, the following 10 cultivars had an average rate of dead plants of 4.7\%-26.4\%: 'Fukuyutaka', 'Toyomusume', 'Ryuhou', 'Miyagishirome', 'Tamahomare', 'Sachiyutaka', 'Yukihomare', 'Tanbakuro', 'Satonohohoemi', and 'Osuzu'. There were no significant differences in the rates of dead plants following the inoculations at 14 and 21 days after seeding for 'Himeshirazu', 'Nattosyoryu', 'Tachinagaha', 'Toyomusume', 'Suzumaru', 'Ryuhou', 'Tamahomare', 'Yukihomare', 'Toyokomachi', and 'Satonohohoemi'. For the other cultivars, the rates of dead plants were significantly lower for the inoculations at 21 days after seeding (Tukey's HSD test, $p<0.01$ ). Of the plants grown for 28 days before being inoculated, only 'Himeshirazu' exhibited a significantly decreased degree

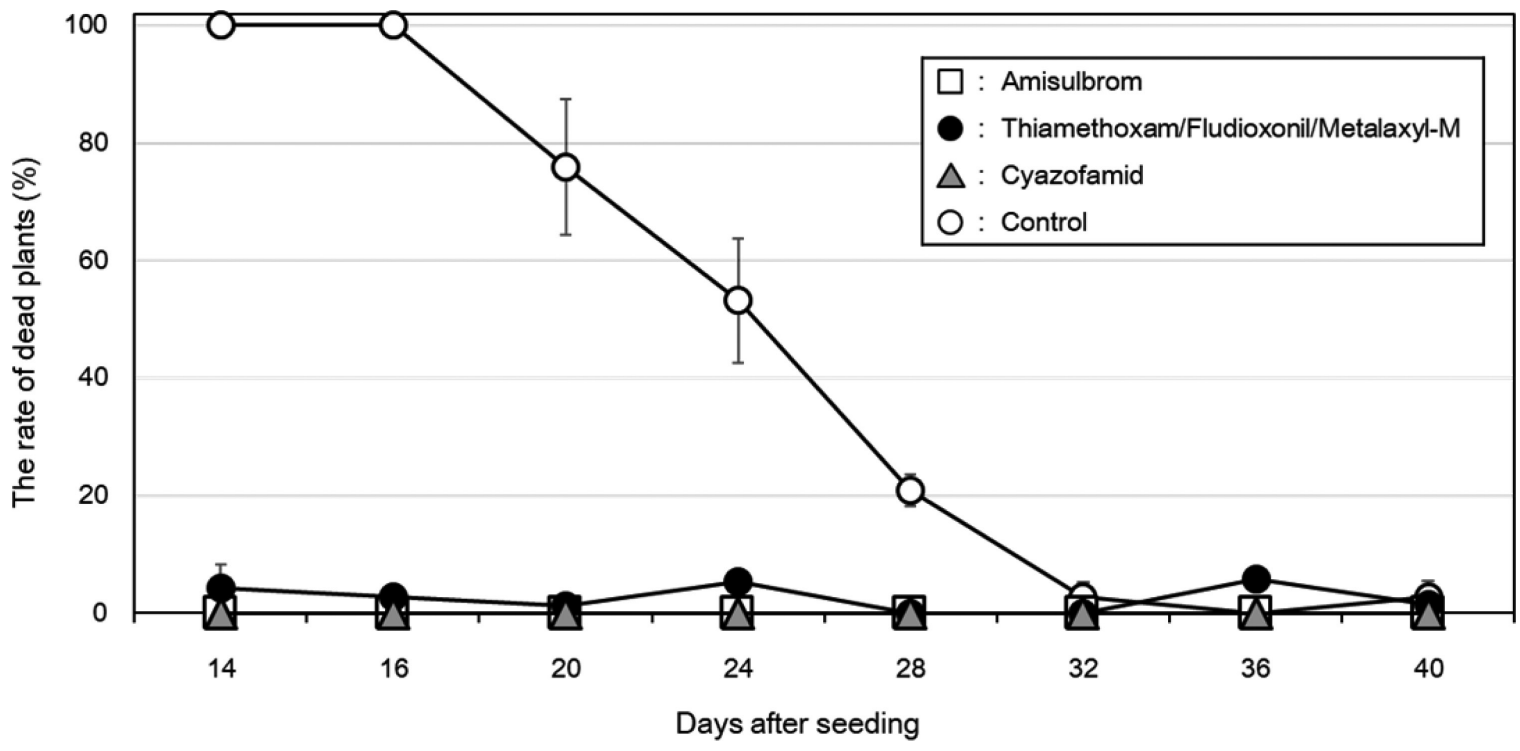

Fig. 4. Effects of a seed treatment with pesticides on the development of Phytophthora root and stem rot. 'Nattosyoryu' seeds treated with one of three pesticides containing fungicidal ingredients were sown, and plants grown for specific periods (14-40 days) were inoculated with Phytophthora sojae isolate 13-B-RO-1. The graph represents a plot of the mean rates of dead plants \pm standard errors (\%) for plants derived from pesticide-treated seeds (white square: amisulbrom; black circle: thiamethoxam, fludioxonil, and metalaxyl-M; grey triangle: cyazofamid) and non-treated controls (white circle). The mean values were significantly different between pesticide-treated samples and non-treated controls following inoculations at 14, 16, 20, 24, and 28 days after seeding according to Dunnett's multiple comparisons test $(p<0.001)$. 
of resistance against the $P$. sojae isolates (Tukey's HSD test, $p<0.01$ ). The average rate of dead plants for 'Himeshirazu' was $32.3 \%$, which was considerably higher than the corresponding rate for the 17 other cultivars $(0.2-2.5 \%)$. Moreover, for all cultivars, the average rates of dead plants were lower for the inoculations at 28 days after seeding than for the inoculations at 14 days after seeding (Tukey's HSD test, $p<0.01$ ). Thus, the inoculation test involving 18 Japanese cultivars and $17 P$. sojae isolates revealed that the disease responses of the cultivars differed depending on the isolate used and the plant ages when inoculated.

The average rates of dead plants for the US cultivars, 'Williams' and 'Harosoy', were $91.2 \%$ and $69.1 \%$, respectively, following the inoculation at 14 days after seeding. These averages for 'Williams' and 'Harosoy' decreased to $43.4 \%$ and $36.6 \%$, respectively, following the inoculation at 21 days after seeding, and decreased further to $5.7 \%$ and $5.3 \%$, respectively, following the inoculation at 28 days after seeding (Tukey's HSD test, $p<0.01$ ).

The results described herein indicated that the resistance levels against $P$. sojae isolates varied among the tested Japanese soybean cultivars. Additionally, none of the cultivars were completely resistant to all $P$. sojae isolates during the seedling and young plant stages. Moreover, for all cultivars, greater resistance (i.e., fewer dead plants) was observed with increasing plant age prior to inoculation. However, the plant ages at which the number of dead plants significantly decreased varied among the cultivars.

The effects of pesticide treatments of soybean seeds on the development of Phytophthora root and stem rot during the early soybean growth stages were investigated using three registered agrochemicals (Table 3, Fig. 4). The active ingredients against $P$. sojae in the three pesticides are amisulbrom, metalaxyl-M, and cyazofamid (Table 3). The rates of 'Nattosyoryu' plants killed by a $P$. sojae infection were significantly lower for the seed-treated samples than for the non-treated controls following the inoculations at 14,16 , 20, 24, and 28 days after seeding (Dunnett's test, $p<0.001$ ). For the inoculations at 32,36 , and 40 days after seeding, an average of $\leq 5.8 \%$ of 'Nattosyoryu' plants were killed regardless of whether seeds were treated with the pesticides. This result suggested that the three pesticides can control the pathogen during the growth period important for stand establishment. Additionally, the pesticide-induced decrease in the number of dead plants due to the pathogen was maintained for at least 28 days after treated seeds were sown.

To investigate the efficacy of the pesticides against different $P$. sojae isolates, 'Nattosyoryu' plants were grown for 14 days after the seeds treated with the pesticides containing metalaxyl-M and cyazofamid were sown. The plants resulting from the seeds treated with metalaxyl-M were then challenged with the following seven $P$. sojae isolates: 13-B-RO-1, 13-B-RO-2, 13-7-B1-1, 13-8-11-2, Ps1001, Ps080806-3-5, and Ps060626-4-1. Meanwhile, the plants that emerged from seeds treated with cyazofamid were inoculated with the same $P$. sojae isolates, except for 13-B-RO-2. The number of dead plants significantly decreased in response to both pesticides (Fig. 5, Dunnett's test, $p<0.05$ ). The average rate of dead plants for the nontreated controls was $72.7 \%-100 \%$, while the correspond-
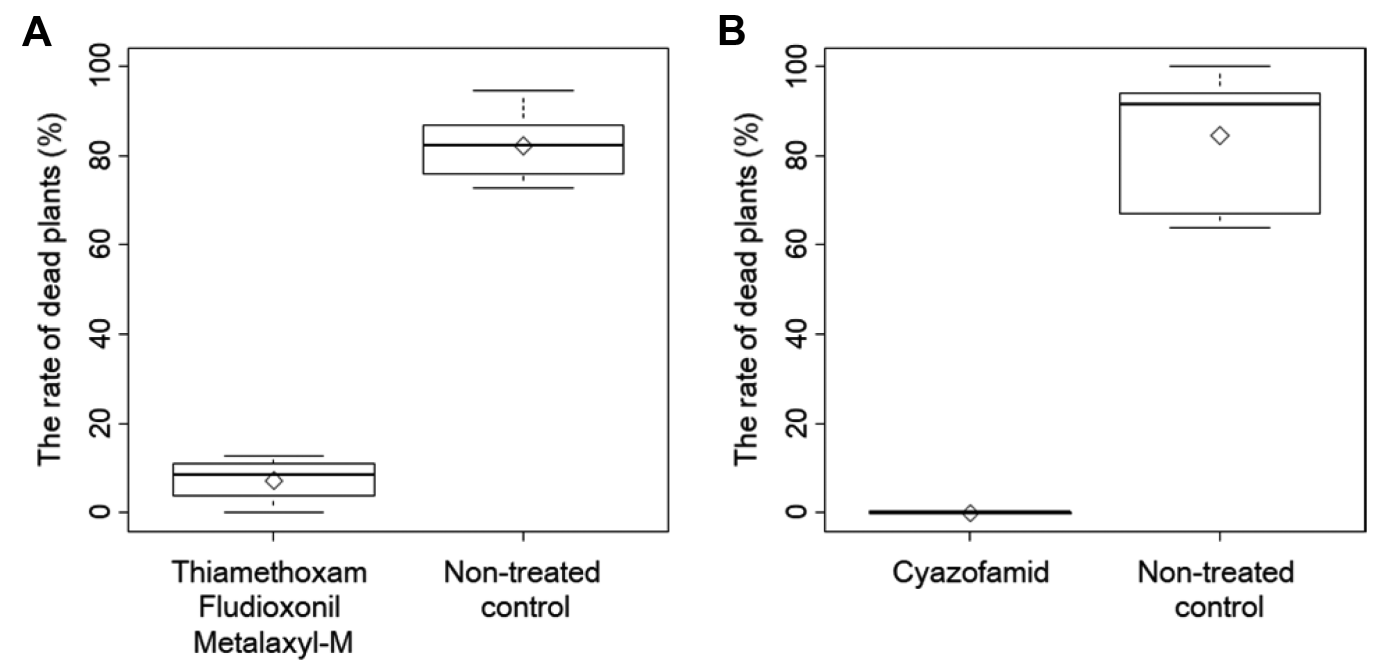

Fig. 5. Effect of a seed treatment with pesticides on the inoculation with different Phytophthora sojae isolates. 'Nattosyoryu' seeds were treated with thiamethoxam, fludioxonil, and metalaxyl-M (A), or cyazofamid (B), and plants grown for 14 days after sown were inoculated with $P$. sojae isolates. The boxplots were drawn based on the rates of dead plants (\%) caused by the inoculation. The open diamond in the plots indicates the average rate of dead plants for each treatment. 
ing rate for the samples treated with metalaxyl-M was $0 \%-12.7 \%$. Regarding the cyazofamid-treated samples, under the conditions in which an average of $63.7 \%-100 \%$ non-treated control plants were killed by the six $P$. sojae isolates, all of the pesticide-treated samples survived the inoculations.

\section{Discussion}

Phytophthora root and stem rot of soybean has threatened Japanese soybean production, especially when $P$. sojae infections occur during the early soybean growth stages. Soybean cultivation in Japan mainly involves the use of converted rice paddy fields. However, such a crop rotation system is favorable for P. sojae infections and disease development because of the soil type and poor drainage of the converted fields (Kato et al., 2013; Sugimoto et al., 2012). Vertical resistance via the expression of Rps genes provides complete protection from the corresponding pathogen races/populations (Dorrance, 2018), but Rps genes have not been exploited in Japan. Thus, the onset of Phytophthora root and stem rot during the early part of the soybean growing season leads to seed rot and seedling damping-off, with adverse consequences for stand establishment (Kato et al., 2013; Schmitthenner and Dorrance, 2015). In this study, we assessed the disease resistance of Japanese soybean cultivars, including the most widely grown cultivars in terms of planted area, by inoculating the aboveground part of the lower hypocotyl. Although none of the Japanese soybean cultivars were totally resistant to all tested $P$. sojae isolates during the first month after seeding, all cultivars exhibited increased resistance when plants were grown for more than 14 days after seeding before being inoculated. Additionally, a seed treatment with one of three pesticides protected soybean plants from $P$. sojae during the early vegetative growth phase, which is an important period for stand establishment. The protective effects of the pesticides were observed for at least 28 days after the treated seeds were sown. In the absence of strong resistance, like that mediated by Rps gene expression, in soybean seeds or seedlings immediately after germination, certain practices (e.g., seed treatments with agrochemicals) are needed to protect soybean plants from $P$. sojae infections during the early growth stages.

In this study, we evaluated the resistance of Japanese soybean cultivars to Phytophthora root and stem rot using a $P$. sojae-V8 culture flooding method modified from the procedure described by Mukobata and Sekihara (2005). Diverse inoculation methods have been developed, including the hypocotyl inoculation, greenhouse inoculum-layer test, and slant-board test as well as the application of a zoospore suspension and a mixture of agar culture homogenate and soil (Dorrance et al., 2004b, 2008; Dorrance and McClure, 2001; Guérin et al., 2014; Jiang et al., 2017; Stewart and Robertson, 2012; Sugimoto et al., 2006; Tooley and Grau, 1982). Some of these methods are used to evaluate complete resistance (e.g., Rps-mediated resistance), while others have been designed to assess incomplete resistance. In our method, the $P$. sojae agar culture is directly added to the water flooding the vermiculite in pots. Zoospores from the sporangia in the water initiate the infection, likely reproducing the soybean-pathogen interactions in the aboveground part of the lower hypocotyl when soybean plants are waterlogged during the early part of the growing season. This inoculation method enables $P$. sojae zoospores to mainly infect the aboveground part of the lower hypocotyl because negative geotaxis causes the zoospores to accumulate near the water surface (Cameron and Carlile, 1977). The damage to the lower hypocotyl caused by $P$. sojae severely inhibits soybean growth because of poor transport of water and/or nutrients from the roots to the upper plant parts, which leads to the damping-off of soybean seedlings and young plants. Our simple inoculation method does not require special techniques or expertise and results in the consistent induction of disease symptoms in soybean plants during the early vegetative growth phase. Moreover, this inoculation method revealed that the tested Japanese cultivars are differentially resistant to $P$. sojae. Although there is relatively little available information regarding the presence/absence of Rps genes in Japanese soybean cultivars (Athow et al., 1980; Rennie et al., 1992; Sugimoto et al., 2011, 2012), some of the tested cultivars were highly resistant to certain $P$. sojae isolates, suggesting that such strong resistance responses may be attributed to a race-specific resistance via the expression of Rps genes. A published report recommended the use of the hypocotyl inoculation test to assess Rps-mediated resistance to ensure $P$. sojae isolates compatible with the tested Japanese soybean cultivars prior to an evaluation of incomplete resistance (Dorrance et al., 2008). Because Rps-mediated resistance was not the focus of our study, compatible/incompatible interactions between the 18 Japanese cultivars and the $17 P$. sojae isolates were not assessed before applying the $P$. sojae-V8 culture flooding method to evaluate the resistance of Japanese cultivars to $P$. sojae at different plant ages.

Partial resistance cannot completely prevent pathogen multiplication, while tolerance refers to the ability of the plant host to endure the presence of the pathogen (Parlevliet, 1979). In soybean, both resistance types are equivalently applied along with quantitative resistance, field resistance, 
and rate-reducing resistance (Dorrance, 2018; Schmitthenner, 1985). Tolerance to Phytophthora root and stem rot is defined as a relative characteristic based on the degree of plant loss or the decrease in growth or yield in the presence of the pathogen races for which a soybean cultivar lacks specific resistance genes (Anderson and Buzzell, 1982). Although it is unclear whether Japanese soybean cultivars carry certain Rps genes, we observed that the resistance of the tested soybean cultivars increased as the age of the plants when inoculated increased (i.e., decrease in the extent of plant death caused by the $P$. sojae infection). The inoculation of plants at 14 days after seeding revealed that six Japanese cultivars ('Himeshirazu', 'Nattosyoryu', 'Enrei', 'Suzumaru', 'Hatayutaka', and 'Osuzu') had an average rate of dead plants that exceeded $75 \%$. With the exception of 'Miyagishirome', the other cultivars were also highly susceptible to certain $P$. sojae isolates. Thus, the resistance of the Japanese cultivars to $P$. sojae infections is not fully expressed in 14-day-old plants, in which the first trifoliate leaves are usually expanding or have expanded. Depending on the cultivars, the average rates of dead plants following a $P$. sojae infection significantly decreased when plants were inoculated at 21 or 28 days after seeding. Considering the partial resistance of soybean to Phytophthora root and stem rot is effective during or after the growth stage when the first trifoliate leaf forms (Dorrance and McClure, 2001; Schmitthenner and Dorrance, 2015), the plant age-dependent resistance observed in this study may be an example of partial resistance to the Japanese P. sojae isolates. Several plant species exhibit a disease resistance at various developmental stages, with varying levels depending on plant age or tissue maturity (Develey-Rivière and Galiana, 2007). The relationship between plant age/ maturity and disease resistance has been studied in a soybean-P. sojae pathosystem (Dorrance and McClure, 2001; Jimenez and Lockwood, 1980; Lazarovits et al., 1981; Paxton and Chamberlain, 1969). Consistent with the results described herein, soybean plants reportedly become more resistant to $P$. sojae as they mature. For example, a previous study revealed that nine susceptible cultivars grown for 7 days before being inoculated were killed by $P$. sojae at a rate of $90 \%$ or higher, while the same cultivars grown for 21 days before being inoculated died at a rate of $30 \%$ or lower (Paxton and Chamberlain, 1969). In the hypocotyl, newer tissues are more susceptible to $P$. sojae than older tissues (Lazarovits et al., 1981). Additionally, an inoculation of 'Altona' plants grown for 6 days with zoospores of an incompatible race 4 isolate reportedly induces a resistance reaction in all hypocotyl parts, implying that the Rpsmediated incompatible interaction has been established in 6-day-old hypocotyls. The observed diseased or dead plants resulting from the inoculation of Japanese soybean cultivars at 14 days after seeding, suggests there is a lack of strong Rps-mediated resistance in most cultivar-isolate interactions at this plant growth stage. Soybean cultivar 'Conrad', which does not carry Rps genes and expresses a high level of partial resistance (Fehr et al., 1989), is highly susceptible to $P$. sojae infections at 0-5 days after seeding, with a seedling emergence rate significantly lower than that of plants inoculated later (Dorrance and McClure, 2001). Jimenez and Lockwood (1980) observed that even 'Hark', which is a susceptible cultivar with little field tolerance, exhibits increased resistance to $P$. sojae when plants are inoculated at 16 days after seeding or later. In the current study, the rates of dead plants due to a $P$. sojae infection for two susceptible cultivars, 'Himeshirazu' and 'Nattosyoryu', were significantly lower for plants inoculated at 25 and 26 days after seeding or later than for plants inoculated at 16-21 days and 16-18 days after seeding, respectively. The resistance of these two cultivars may not be expressed as quickly as that of 'Conrad'. Although different inoculation and evaluation protocols were used, disease resistance increased as the age of plants at inoculation increased for all of the tested Japanese soybean cultivars, which is consistent with the results of previous studies (Dorrance and McClure, 2001; Jimenez and Lockwood, 1980; Lazarovits et al., 1981; Paxton and Chamberlain, 1969). The plant ages associated with increases in resistance varied among the cultivars, but the timing of the expression of resistance in the Japanese cultivars is likely consistent with that of partial resistance (Schmitthenner and Dorrance, 2015). Varying levels of partial resistance to $P$. sojae were shown in 'Conrad' and 'Sloan' hypocotyls, while a lack of partial resistance was observed in the roots of these two cultivars (Yamamoto et al., unpublished). However, partial resistance to $P$. sojae is reportedly expressed in the roots of cultivars with high levels of resistance (i.e., limited root rot and the absence of stem rot) (Dorrance et al., 2007; Mideros et al., 2007; Schmitthenner, 1985; Tooley and Grau, 1984). The partial resistance expression site in the current study might be inconsistent with that of several other studies that assessed root damage (Abeysekara et al., 2016; Burnham et al., 2003; Jia and Kurle, 2008; Lee et al., 2013a, 2013b; McBlain et al., 1991; Schneider et al., 2016; Stewart and Robertson, 2012; Tucker et al., 2010; Wu et al., 2011). This discrepancy was likely because our evaluation was based on the damping-off elicited by the severe infection around the lower hypocotyl and not root damage.

This study also determined the effective period for the treatment of seeds with three pesticides to provide pro- 
tection against $P$. sojae. The active ingredients against Phytophthora root and stem rot in these pesticides are amisulbrom, metalaxyl-M, and cyazofamid. Metalaxyl-M, which is also known as mefenoxam, is the active isomer of metalaxyl, and is grouped with the phenylamide fungicides (Hirooka and Ishii, 2013), which are among the most commonly applied agrochemicals worldwide to control diverse oomycete-induced diseases (Dorrance, 2018; Dorrance et al., 2004a, 2007; Matheron and Porchas, 2014; Schmitthenner and Dorrance, 2015; Taylor et al., 2002). Meanwhile, amisulbrom and cyazofamid are quinone inside inhibitors that have similar protective effects against foliar and tuber blight caused by Phytophthora infestans (Hirooka and Ishii, 2013; Honda et al., 2007). Cyazofamid strongly inhibits the mycelial growth of oomycete species, with 0.2 $\mu \mathrm{g} / \mathrm{ml}$ representing an effective concentration for inhibiting $P$. sojae growth by $50 \%$ (Mitani et al., 2001). At least 0.5 $\mu \mathrm{g} / \mathrm{ml}$ is needed for an inhibition exceeding $90 \%$, similar to metalaxyl. Additionally, mefenoxam is more effective than cyazofamid against Phytophthora capsici, with lesion development inhibited for at least 3 weeks when applied to roots (Matheron and Porchas, 2014). Although the three active ingredients are highly specific for oomycetes, previous studies focused primarily on the protective effects of metalaxyl and metalaxyl-M against Phytophthora root and stem rot of soybean (Anderson and Buzzell, 1982; Dorrance and McClure, 2001; Dorrance et al., 2009; Guy et al., 1989; Vaartaja et al., 1979). There have been relatively few studies examining the effects of amisulbrom and cyazofamid on soybean-P. sojae interactions (Mimuro, 2011). The current study revealed that the rates of dead plants due to $P$. sojae infections decreased significantly after seeds were treated with the pesticides. The protection provided by the pesticides continued for 28 days after the treatment. Because few plants were killed in the non-treated control at 29 days or later, the effective periods for these pesticides were not determined in this study. Mimuro (2011) reported that these three pesticides can protect soybean plants from Phytophthora root and stem rot for approximately 1 month after treated seeds are sown, which is consistent with our findings as well as the effective period indicated by the manufacturer of the pesticide containing metalaxyl-M.

According to industry estimates, the treatment of soybean seeds with pesticides has dramatically increased from $<8 \%$ in 1996 to $>30 \%$ in 2008 , which has improved disease management during the early part of the soybean growing season (Esker and Conley, 2012; Munkvold, 2009). Soybean cultivation in Japan has recently become increasingly dependent on seed treatments, mainly with metalaxyl-M-containing pesticides. This is because soy- bean plants grown in fields converted from rice paddies are at high risk of being infected by $P$. sojae. Although seed treatments with pesticides are important for protecting young soybean plants from $P$. sojae and enhancing stand establishment, the pesticides are costly and repeated applications of the same pesticide may decrease the sensitivity of $P$. sojae to the active ingredient (i.e., pesticide resistance) (Han et al., 2011; Hunger et al., 1982). Planting cultivars exhibiting complete and/or incomplete disease resistance may be a more economically viable option for combating Phytophthora root and stem rot of soybean. Consequently, a comprehensive characterization of the disease resistance in Japanese cultivars via an analysis of $R p s$ genes may be important for elucidating the Japanese soybean- $P$. sojae pathosystem and may be useful for the development of new lines/cultivars that are resistant to Phytophthora root and stem rot. The fact that none of the 18 tested Japanese cultivars were completely resistant to all of the $P$. sojae isolates following inoculations at 14 days after seeding suggests these cultivars likely do not express effective resistance during the early growth stages. Thus, additional practices, such as seed treatments with agrochemicals, will need to be implemented, especially if these soybean cultivars lack Rps-mediated resistance and are grown in disease-conducive environments, including fields previously infected by $P$. sojae and fields that have been waterlogged for prolonged periods.

\section{Acknowledgements}

We gratefully acknowledge technical staffs of Central Region Agricultural Research Center of National Agriculture and Food Research Organization for their technical assistance. We also thank Edanz Group (www.edanzediting. $\mathrm{com} / \mathrm{ac}$ ) for editing a draft of this manuscript. This research was supported by the Commissioned Project Study entitled "Development of Soybean and Buckwheat Cultivars with Processability and Wide Area Adaptability According to the Users' Needs" from the Ministry of Agriculture, Forestry and Fisheries of Japan.

\section{References}

Abeysekara, N. S., Matthiesen, R. L., Cianzio, S. R., Bhattacharyya, M. K. and Robertson, A. E. 2016. Novel sources of partial resistance against Phytophthora sojae in soybean PI 399036. Crop Sci. 56:2322-2335.

Anderson, T. R. and Buzzell, R. I. 1982. Efficacy of metalaxyl in controlling Phytophthora root and stalk rot of soybean cultivars differing in field tolerance. Plant Dis. 66:1144-1145.

Anderson, T. R. and Buzzell, R. I. 1992. Inheritance and linkage 
of the Rps 7 gene for resistance to Phytophthora rot of soybean. Plant Dis. 76:958-959.

Athow, K. L., Laviolette, F. A., Mueller, E. H. and Wilcox, J. R. 1980. A new major gene for resistance to Phytophthora megasperma var. sojae in soybean. Phytopathology 70:977980.

Bienapfl, J. C., Malvick, D. K. and Percich, J. A. 2011. Specific molecular detection of Phytophthora sojae using conventional and real-time PCR. Fungal Biol. 115:733-740.

Burnham, K. D., Dorrance, A. E., VanToai, T. T. and St. Martin, S. K. 2003. Quantitative trait loci for partial resistance to Phytophthora sojae in soybean. Crop Sci. 43:1610-1617.

Cameron, J. N. and Carlile, M. J. 1977. Negative geotaxis of zoospores of the fungus Phytophthora. J. Gen. Microbiol. 98:599-602.

Chen, H. 2018. The spatial patterns in long-term temporal trends of three major crops' yields in Japan. Plant Prod. Sci. 21:177185.

Develey-Rivière, M. P. and Galiana, E. 2007. Resistance to pathogens and host developmental stage: a multifaceted relationship within the plant kingdom. New Phytol. 175:405-416.

Dorrance, A. E. 2018. Management of Phytophthora sojae of soybean: a review and future perspectives. Can. J. Plant Pathol. 40:210-219.

Dorrance, A. E. and Schmitthenner, A. F. 2000. New sources of resistance to Phytophthora sojae in the soybean plant introductions. Plant Dis. 84:1303-1308.

Dorrance, A. E. and McClure, S. A. 2001. Beneficial effects of fungicide seed treatment for soybean cultivars with partial resistance to Phytophthora sojae. Plant Dis. 85:1063-1068.

Dorrance, A. E., Berry, S. A., Bowen, P. and Lipps, P. E. 2004a. Characterization of Pythium spp. from three Ohio fields for pathogenicity on corn and soybean and metalaxyl sensitivity. Plant Health Prog. doi: 10.1094/PHP-2004-0202-01-RS.

Dorrance, A. E., Jia, H. and Abney, T. S. 2004b. Evaluation of soybean differentials for their interaction with Phytophthora sojae. Plant Health Prog. doi: 10.1094/PHP-2004-0309-01RS.

Dorrance, A. E., Mills, D., Robertson, A. E., Draper, M. A., Giesler, L. and Tenuta, A. 2007. Phytophthora root and stem rot of soybean. Plant Health Instr. doi: 10.1094/PHII-2007-0830-07.

Dorrance, A. E., Berry, S. A., Anderson, T. R. and Meharg, C. 2008. Isolation, storage, pathotype characterization, and evaluation of resistance for Phytophthora sojae in soybean. Plant Health Prog. doi: 10.1094/PHP-2008-0118-01-DG.

Dorrance, A. E., Robertson, A. E., Cianzo, S., Giesler, L. J., Grau, C. R., Draper, M. A., Tenuta, A. U. and Anderson, T. R. 2009. Integrated management strategies for Phytophthora sojae combining host resistance and seed treatments. Plant Dis. 93:875-882.

Esker, P. D. and Conley, S. P. 2012. Probability of yield response and breaking even for soybean seed treatments. Crop Sci. 52:351-359.
FAOSTAT. 2016. FAOSTAT statistical databases. Food and Agriculture Organization of the United Nations, Rome. URL http://www.fao.org/faostat/en/\#data/QC [26 June 2018].

Fehr, W. R., Cianzio, S. R., Voss, B. K. and Schultz, S. P. 1989. Registration of "Conrad" soybean. Crop Sci. 29:830.

Förster, H., Coffey, M. D., Elwood, H. and Sogin, M. L. 1990. Sequence analysis of the small subunit ribosomal RNAs of three zoosporic fungi and implications for fungal evolution. Mycologia 82:306-312.

Fungicide Resistance Action Committee. 2018. FRAC Code List 2018: fungicides sorted by mode of action (including FRAC Code numbering). URL http://www.phi-base.org/images/fracCodeList.pdf [14 May 2019].

Grau, C. R., Dorrance, A. E., Bond, J. and Russin, J. S. 2004. Fungal diseases. In: Soybeans: improvement, production, and uses, eds. by H. R. Boerma and J. E. Specht, pp. 679-764. American Society of Agronomy, Madison, WI, USA.

Guérin, V., Lebreton, A., Cogliati, E. E., Hartley, S. E., Belzile, F., Menzies, J. G. and Bélanger, R. R. 2014. A zoospore inoculation method with Phytophthora sojae to assess the prophylactic role of silicon on soybean cultivars. Plant Dis. 98:16321638.

Guy, S. O., Oplinger, E. S. and Grau, C. R. 1989. Soybean cultivar response to metalaxyl applied in furrow and as a seed treatment. Agron. J. 81:529-532.

Han, Q., Zhao, H., Huang, L., Buchenauer, H., Zuo, Y. and Kang, Z. 2011. Light and electron microscopy studies on the infection of a wild-type and metalaxyl-resistant isolate of Phytophthora sojae in soybean hypocotyls. J. Phytopathol. 159:368376.

Hansen, E. M. and Maxwell, D. P. 1991. Species of the Phytophthora megasperma complex. Mycologia 83:376-381.

Harper, J. T., Waanders, E. and Keeling, P. J. 2005. On the monophyly of chromalveolates using a six-protein phylogeny of eukaryotes. Int. J. Syst. Evol. Microbiol. 55:487-496.

Hartman, G. L., West, E. D. and Herman, T. K. 2011. Crops that feed the world 2. soybean-worldwide production, use, and constraints caused by pathogens and pests. Food Sec. 3:5-17.

Hirooka, T. and Ishii, H. 2013. Chemical control of plant diseases. J. Gen. Plant Pathol. 79:390-401.

Honda, T., Hasunuma, N. and Nishioka, M. 2007. Amisulbrom (NC-224): performance of new fungicide for potato late blight control. In: Proceedings of the tenth workshop of an European network for development of an integrated control strategy of potato late blight, ed. by H. T. A. M. Schepers, pp. 59-65. Bologna, Italy.

Hunger, R. M., Hamm, P. B., Horner, C. E. and Hansen, E. M. 1982. Tolerance of Phytophthora megasperma isolates to metalaxyl. Plant Dis. 66:645-649.

Jia, H. and Kurle, J. E. 2008. Resistance and partial resistance to Phytophthora sojae in early maturity group soybean plant introductions. Euphytica 159:27-34.

Jiang, C. J., Sugano, S., Kaga, A., Lee, S. S., Sugimoto, T., Takahashi, M. and Ishimoto, M. 2017. Evaluation of resistance to 
Phytophthora sojae in soybean mini core collections using an improved assay system. Phytopathology 107:216-223.

Jimenez, B. and Lockwood, J. L. 1980. Laboratory method for assessing field tolerance of soybean seedlings to Phytophthora megasperma var. sojae. Plant Dis. 64:775-778.

Kato, M., Minamida, K., Tojo, M., Kokuryu, T., Hamaguchi, H. and Shimada, S. 2013. Association of Pythium and Phytophthora with pre-emergence seedling damping-off of soybean grown in a field converted from a paddy field in Japan. Plant Prod. Sci. 16:95-104.

Kaufmann, M. J. and Gerdemann, J. W. 1958. Root and stem rot of soybean caused by Phytophthora sojae n. sp. Phytopathology 48:201-208.

Lazarovits, G., Stössel, R. and Ward, E. W. B. 1981. Age-related changes in specificity and glyceollin production in the hypocotyl reaction of soybeans to Phytophthora megasperma var. sojae. Phytopathology 71:94-97.

Lee, S., Rouf Mian, M. A., McHale, L. K., Sneller, C. H. and Dorrance, A. E. 2013a. Identification of quantitative trait loci conditioning partial resistance to Phytophthora sojae in soybean PI 407861A. Crop Sci. 53:1022-1031.

Lee, S., Rouf Mian, M. A., McHale, L. K., Wang, H., Wijeratne, A. J., Sneller, C. H. and Dorrance, A. E. 2013b. Novel quantitative trait loci for partial resistance to Phytophthora sojae in soybean PI 398841. Theor. Appl. Genet. 126:1121-1132.

Matheron, M. E. and Porchas, M. 2014. Effectiveness of 14 fungicides for suppressing lesions caused by Phytophthora capsici on inoculated stems of chile pepper seedlings. Plant Health Prog. 15:166-171.

McBlain, B. A., Hacker, J. K., Zimmerly, M. M. and Schmitthenner, A. F. 1991. Tolerance to Phytophthora rot in soybean: II. Evaluation of three tolerance screening methods. Crop Sci. 31:1412-1417.

Mideros, S., Nita, M. and Dorrance, A. E. 2007. Characterization of components of partial resistance, Rps2, and root resistance to Phytophthora sojae in soybean. Phytopathology 97:655662.

Mimuro, G. 2011. Control of Phytophthora root and stem rot of soybean by seed treatment with fungicides and amelioration of soil acidity. Plant Prot. 65:351-355 (in Japanese).

Mitani, S., Araki, S., Yamaguchi, T., Takii, Y., Ohshima, T. and Matsuo, N. 2001. Antifungal activity of the novel fungicide cyazofamid against Phytophthora infestans and other plant pathogenic fungi in vitro. Pestic. Biochem. Physiol. 70:92-99.

Moriwaki, J. 2010. Aiming at the construction of the race distinction system of Japanese Phytophthora sojae. Plant Prot. 64:508-510 (in Japanese).

Mukobata, H. and Sekihara, J. 2006. Occurrence of Phytophthora root and stem rot of soybean in various places in Toyama Prefecture in 2002. Proc. Assoc. Plant Prot. Hokuriku 55:27-32 (in Japanese).

Munkvold, G. P. 2009. Seed pathology progress in academia and industry. Annu. Rev. Phytopathol. 47:285-311.

Parlevliet, J. E. 1979. Components of resistance that reduce the rate of epidemic development. Annu. Rev. Phytopathol. 17:203-222.

Paxton, J. D. and Chamberlain, D. W. 1969. Phytoalexin production and disease resistance in soybeans as affected by age. Phytopathology 59:775-777.

R Core Team. 2018. R: A language and environment for statistical computing. R Foundation for Statistical Computing, Vienna. URL http:/www.r-project.org/ [15 March 2018]

Rennie, B. D., Buzzell, R. I., Anderson, T. R. and Beversdorf, W. D. 1992. Evaluation of four Japanese soybean cultivars for Rps alleles conferring resistance to Phytophthora megasperma f. sp. glycinea. Can. J. Plant Sci. 72:217-220.

Schmitthenner, A. F. 1985. Problems and progress in control of Phytophthora root rot of soybean. Plant Dis. 69:362-368.

Schmitthenner, A. F. and Dorrance, A. E. 2015. Phytophthora root and stem rot. In: Compendium of soybean diseases and pests, eds. by G. L. Hartman, J. C. Rupe, E. J. Sikora, L. L. Domier, J. A. Davis, and K. L. Steffey, pp. 73-76. The American Phytopathological Society Press, St. Paul, MN, USA.

Schneider, R., Rolling, W., Song, Q., Cregan, P., Dorrance, A. E. and McHale, L. K. 2016. Genome-wide association mapping of partial resistance to Phytophthora sojae in soybean plant introductions from the Republic of Korea. BMC Genomics 17:607.

Stewart, S. and Robertson, A. E. 2012. A modified method to screen for partial resistance to Phytophthora sojae in soybean. Crop Sci. 52:1181-1186.

Sugimoto, T., Yoshida, S., Aino, M., Watanabe, K., Shiwaku, K. and Sugimoto, M. 2006. Race distribution of Phytophthora sojae on soybean in Hyogo, Japan. J. Gen. Plant Pathol. 72:92-97.

Sugimoto, T., Yoshida, S., Kaga, A., Hajika, M., Watanabe, K., Aino, M., Tatsuda, K., Yamamoto, R., Matoh, T., Walker, D. R., Biggs, A. R. and Ishimoto, M. 2011. Genetic analysis and identification of DNA markers linked to a novel Phytophthora sojae resistance gene in the Japanese soybean cultivar Waseshiroge. Euphytica 182:133-145.

Sugimoto, T., Kato, M., Yoshida, S., Matsumoto, I., Kobayashi, T., Kaga, A., Hajika, M., Yamamoto, R., Watanabe, K., Aino, M., Matoh, T., Walker, D. R., Biggs, A. R. and Ishimoto, M. 2012. Pathogenic diversity of Phytophthora sojae and breeding strategies to develop Phytophthora-resistant soybeans. Breed Sci. 61:511-522.

Taylor, R. J., Salas, B., Secor, G. A., Rivera, V. and Gudmestad, N. C. 2002. Sensitivity of North American isolates of Phytophthora erythroseptica and Pythium ultimum to mefenoxam (metalaxyl). Plant Dis. 86:797-802.

Tooley, P. W. and Grau, C. R. 1982. Identification and quantitative characterization of rate-reducing resistance to Phytophthora megasperma f. sp. glycinea in soybean seedlings. Phytopathology 72:727-733.

Tooley, P. W. and Grau, C. R. 1984. Field characterization of ratereducing resistance to Phytophthora megasperma f. sp. glycinea and yield of soybean. Phytopathology 74:1201-1208. 
Tucker, D. M., Maroof, S., Mideros, S., Skoneczka, J. A., Nabati, D. A., Buss, G. R., Hoeschele, I., Tyler, B. M., St. Martin, S. K. and Dorrance, A. E. 2010. Mapping quantitative trait loci for partial resistance to Phytophthora sojae in a soybean interspecific cross. Crop Sci. 50:628-635.

Tyler, B. M. 2007. Phytophthora sojae: root rot pathogen of soybean and model oomycete. Mol. Plant Pathol. 8:1-8.

Vaartaja, O., Pitblado, R. E., Buzzell, R. I. and Crawford, L. G. 1979. Chemical and biological control of Phytophthora root and stalk rot of soybean. Can. J. Plant Sci. 59:307-311.

Wrather, J. A., Anderson, T. R., Arsyad, D. M., Tan, Y., Ploper, L. D., Porta-Puglia, A., Ram, H. H. and Yorinori, J. T. 2001a. Soybean disease loss estimates for the top ten soybean-producing countries in 1998. Can. J. Plant Pathol. 23:115-121.
Wrather, J. A., Stienstra, W. C. and Koenning, S. R. 2001b. Soybean disease loss estimates for the United States from 1996 to 1998. Can. J. Plant Pathol. 23:122-131.

Wrather, A. and Koenning, S. 2009. Effects of diseases on soybean yields in the United States 1996 to 2007. Plant Health Prog. doi: 10.1094/PHP-2009-0401-01-RS.

Wu, X., Zhou, B., Zhao, J., Guo, N., Zhang, B., Yang, F., Chen, S., Gai, J. and Xing, H. 2011. Identification of quantitative trait loci for partial resistance to Phytophthora sojae in soybean. Plant Breed. 130:144-149.

Yamashita, Y., Tazawa, A. and Minami, M. 2012. Development of a method to evaluate the field resistance of soybean to $P h y$ tophthora sojae. Jpn. J. Crop Sci. 81:183-189 (in Japanese). 